\title{
Desarrollo de habilidades matemáticas en estudiantes que ingresan a la educación superior
}

\author{
Frey Rodríguez Pérez, Marco Antonio Ramírez
}

Recibido: 23 de febrero de 2015 Aprobado: 25 de mayo de 2015

\section{Resumen}

El Departamento de Ciencias Básicas de UNIMINUTO, sede principal, viene desarrollando un proyecto para disminuir el nivel de pérdida y deserción en los primeros cursos de matemáticas. Para ello se sugieren estrategias didácticas que fortalezcan en los estudiantes habilidades básicas en matemáticas como seguir secuencias, visualizar, tener sentido de orientación y estimar, entre otras. En el primer semestre del 2014 el proyecto se encontraba en la fase piloto o de prueba de una estrategia centrada en los estilos de aprendizaje de Kolb, para lo cual se llevó a cabo un estudio preexperimental de tipo diseño pretest-postest de un solo grupo, según Stanley y Campbell (2005), dirigido a medir el impacto que sobre la motivación, la comunicación y las habilidades básicas tenía la estrategia. Los resultados preliminares permitieron detectar un aumento de cerca del $33 \%$ en el desempeño de habilidades como seguir secuencias, reconocer patrones, estimar e interpretar información cuantitativa. Lo motivacional se fortaleció gracias al tipo de evaluación y a las actividades y recursos centrados en los estilos de aprendizaje. Finalmente, el uso de la red Edmodo favoreció la comunicación, sobre todo en cuanto al tiempo de respuesta.

Palabras claves: didáctica, aprendizaje, TIC, habilidades, matemáticas.

\section{Abstract}

The Department of Basic Sciences UNIMINUTO, has developed a project to reduce the level of loss and desertion in the first courses in mathematics, for it is meant to suggest teaching strategies to strengthen the students basic math skills like following sequences , display, have sense of direction, estimating, among others. In the first half of 2014 the project was in the pilot or proof of a focused learning styles Kolb strategy for which conducted a study of pre-experimental pretest-posttest one group such as Stanley phase and Campbell (2005) to measure the impact on motivation, communication and basic skills was the strategy. In preliminary results an increase was found in more than $33 \%$ in skills like following sequences, recognize patterns, estimate and interpret quantitative information; motivational what is strengthened by the type of evaluation and the activities and resources focusing on learning styles; finally use of EDMODO primarily favored communication network from time response factor.

Key words: teaching, learning, TIC, skills, mathematics.

\footnotetext{
${ }^{1}$ Docentes de tiempo completo. Unidad de Ciencias Básicas. Facultad de Ingeniería de UNIMINUTO.
} 


\section{ANTECEDENTES Y FORMULACIÓN DEL PROBLEMA}

El Departamento de Ciencias Básicas de UNIMINUTO, sede principal, comprometido con la misión institucional de brindar una formación con calidad al alcance de todos, preocupado porque, en promedio, durante los años 2010 y 2011 el nivel de pérdida en asignaturas de primer semestre como precálculo, matemática empresarial y geometría fue cercano al $58 \%$, decidió implementar una prueba de ingreso. Ésta tenía como objetivo identificar los niveles de desempeño inicial de los estudiantes frente a los conceptos por abordar en primer semestre, específicamente desde el pensamiento algebraico y el pensamiento geométrico. Así fue como en la primera prueba, centrada en lo conceptual y aplicada en el primer semestre de 2012 a un total de 761 estudiantes, se estableció que el $88 \%$ de la población se ubicó en un nivel básico con vacíos alrededor de preconceptos propios de la geometría, deficiencias en acciones básicas como visualizar y clasificar, dificultades procedimentales e interpretativas en el manejo de la letra como representación de la incógnita, generalidad frente al número y variable en relación con el objeto función.

La segunda prueba dejó a un lado el peso conceptual y se centró en las habilidades generales del pensamiento matemático, según el Ministerio de Educación Nacional (1998), es decir, la resolución de problemas, la comunicación, la modelización y el uso de diferentes formas de representación. La prueba se aplicó durante el primer semestre de 2013 a un grupo de 763 estudiantes y como resultado se obtuvo que el $78 \%$ de los estudiantes se clasificaron en nivel básico, con dificultades principalmente en comprensión lectora, lógica matemática, visualización y lectura de gráficas. En otras palabras, las dos pruebas permitieron observar que el problema se hallaba en las habilidades fundamentales del pensamiento matemático, además de los altos índices de variación en los resultados de las dos pruebas a pesar de que cumplían con la validez de contenido.

Para el segundo semestre de 2013 se sugirió una tercera prueba centrada en habilidades básicas como identificar secuencias, reconocer patrones, visualizar, estimar, interrelacionar procedimientos, interpretar información cuantitativa, tener sentido de orientación, razonar deductiva e inductivamente. Éstas, según Sharma (2006), soportan el desarrollo de habilidades de pensamiento superior hacia lo abstracto y la aprehensión de nuevos conceptos. La prueba se aplicó en un instrumento de 27 preguntas (tres por habilidad en nivel básico, medio y alto) a 880 estudiantes, de los cuales el $75 \%$ se clasificó en el nivel básico, con menor variación entre toda la población y grados de dificultad similares frente a las habilidades básicas. Además, se aplicó un instrumento para conocer la actitud de los estudiantes frente a la matemática y analizar su incidencia en el desempeño en la prueba de habilidades. Se obtuvieron los niveles medio frente al deseo de saber y la seguridad ante la matemática; medio alto respecto de la utilidad en su campo profesional, y alto en cuanto a la importancia.

Luego de haber detectado que las dificultades de los estudiantes que inician su proceso formativo se centra en el bajo desarrollo de sus habilidades básicas, el Departamento de Ciencias Básicas empezó a sugerir estrategias que permitieran reducir dichas debilidades y errores, para lo cual centró su atención en tres elementos: los estilos de aprendizaje en ambientes digitales desde Kolb (1993), las tecnologías como herramientas mediadoras y la comunicación. Con base en lo anterior, un grupo de docentes sugirió la siguiente pregunta de investigación: ¿Qué impacto tiene una estrategia didáctica centrada en los estilos de aprendizaje de Kolb, convergente, asimilador y acomodador, apoyada en un ambiente virtual y en la red académica Edmodo, en el fortalecimiento de las habilidades básicas del pensamiento matemático de los estudiantes que ingresan a UNIMINUTO sede principal?

\section{MARCO DE REFERENCIA CONCEPTUAL}

Referente pedagógico. Dado que la estrategia no se podía aplicar durante el semestre académico de forma presencial debido a la necesidad de espacios y programación de horarios, se optó por la modalidad e-learning. Adicional a los lineamientos pedagógicos de UNIMINUTO (enfoque praxeológico centrado en la formación integral del estudiante), se tuvieron en cuenta los estilos de aprendizaje según Kolb y la motivación. Para Kolb (1993) los estilos son capacidades para aprender que se destacan, de las experiencias vitales propias y de las exigencias del medio actual; agrega que el aprendizaje se da por las adaptaciones al ambiente que proceden de un diálogo natural recurrente que comienza con la valoración de la experiencia previa del aprendiz. Esta valoración crea el contexto para involucrarse en la percepción mediante la observación y la reflexión.

El sistema de clasificación de Kolb identifica cuatro estilos básicos: los divergentes, que se basan en sus experiencias concretas y las procesan reflexivamente; los asimiladores, que se soportan en teorías y conceptualizaciones abstractas procesando reflexivamente; los convergentes, que dirigen por conceptualizaciones abstractas del mundo y las procesan activamente; y los acomodadores, que se guían por sus experiencias concretas y las procesan activamente. Para el diseño del ambiente virtual no se tuvo en 
cuenta el estilo divergente ya que varios estudios han demostrado que en la formación profesional en tecnologías e ingeniería sobresalen principalmente los estilos convergente, asimilador y acomodador (Ventura, 2014). Especifica, por ejemplo, que el estilo asimilador es una particularidad de los graduados en ciencias básicas y matemática, ya que su punto fuerte reside en el desarrollo de habilidades para crear modelos teóricos y procesar grandes volúmenes de información; el estilo convergente es característico de los ingenieros, ya que su fortaleza reside en la aplicación de conceptos y teorías, tienden a organizar el conocimiento por medio de un tipo de pensamiento hipotético-deductivo y prefieren las situaciones técnicas; y el estilo acomodador es una peculiaridad de profesionales en marketing, negocios y ventas, se caracterizan por ejecutar proyectos y poseer pensamientos de tipo pragmático, en general prefieren guiarse por el empirismo y la intuición resolviendo problemas con técnicas de "ensayo-y-error".

Desde la motivación, para Argüelles y Nagles (2010) es una acción mental que condiciona el pensamiento y con ello el tipo de aprendizaje resultante. Abarca todo el acto educativo, proporciona razones y motivos, es decir, mueve la voluntad hacia el aprendizaje. Dentro de los factores que condicionaron la motivación se encuentran la significatividad y utilidad de los contenidos, el contexto específico en que ocurre la situación de aprendizaje, la forma de pensar, el conocimiento y la posibilidad real que tiene el estudiante de conseguir las metas que se propone. Coll y Monereo (2008) determinaron que existe una diversidad de materiales autosuficientes y entornos digitales diseñados para el aprendizaje autónomo y autodirigido, los cuales se caracterizan de manera explícita o implícita por la concepción del aprendizaje en la que se apoyan; es así como para el diseño de materiales didácticos de autoaprendizaje existen diversas propuestas fundamentadas en los diversos enfoques teóricos: conductista, cognitivo y constructivista. Santoianni y Striano (2006) afirman que el aprendizaje es un proceso resultante de los estímulos, las respuestas, la asimilación de los resultados y la repetición de los mismos; sin embargo, estos autores citan a Thorndike (1930), quien asegura que el verdadero aprendizaje surge de la satisfacción del individuo ante la solución de un problema de forma adecuada (condicionamiento operante). Por último, para Huertas (citado por Bryndum, S. \& Montes, J., 2001) la motivación es "un ensayo mental preparatorio de una acción para animarse a ejecutarla con interés y diligencia", y es un proceso psicológico que determina en todo caso la planificación y la actuación del sujeto, es un estado dinámico más que un estado fijo. Considera seis parámetros para la intervención motivacional en clase, que los sintetiza con el acrónimo Target (en inglés, diana o meta) recogidos por Epstein (1989), ellos son: tarea, autoridad, reconocimiento, grupos, evaluación y tiempo.

De acuerdo con la revisión anterior, en la construcción de la propuesta didáctica y siguiendo a Huertas (2005), en concordancia con Argüelles \& Nagles (2010), se seleccionaron las siguientes variables como elementos relevantes de la motivación: las creencias de control de aprendizaje, el valor tarea, la metodología instruccional, la organización del contenido, el sistema tutorial y el reconocimiento del logro, las cuales se analizarán en relación con el fortalecimiento de las habilidades básicas en matemáticas. Dichas variables fueron seleccionadas, además, por estar directamente vinculadas con el problema institucional objeto de estudio y la solución propuesta.

Referente didáctico o instruccional. Según el tipo de modalidad por implementar, en la estrategia se seleccionó un diseño instruccional (DI) basado en el modelo de Jonassen (1999), de corte constructivista, que enfatiza en el papel del aprendiz en la construcción del conocimiento (aprender haciendo) y permite dinamizar el aprendizaje autorregulado, eje fundamental de la propuesta pedagógica. Su objetivo principal es fomentar la solución de problemas y el desarrollo conceptual a partir de la apropiación que haga el aprendiz de las diversas situaciones y experiencias que le faciliten dar significado a determinadas realidades en contexto y que en últimas le permitan un aprendizaje activo y auténtico. Por otra parte, para el diseño de la navegabilidad en la plataforma informática, en el desarrollo de las actividades se tuvieron en cuenta las cuatro etapas del enfoque praxeológico de UNIMINUTO (2012), el cual está centrado en la formación integral, entendida como aquella que pretende el desarrollo armónico de todas las dimensiones de la persona integrando el saber (teoría) con el actuar (praxis) y es diestra para articular en la sociedad el proyecto de vida y de trabajo que, en sí misma, ha realizado (Juliao, 2011). En el VER, o fase de exploración, se espera que el estudiante indague, se pregunte el porqué de las situaciones; en el JUZGAR, que reaccione ante el dispositivo pedagógico y empiece a buscar posibles soluciones; en el ACTUAR, que encuentre o plantee una solución concreta a los problemas o situaciones planteadas, y en la DEVOLUCIÓN CREATIVA, o fase de anticipación y aplicación, que sea consciente de la habilidad desarrollada.

Referente matemático. Las habilidades básicas del pensamiento matemático se entienden desde Sharma (2006) como aquellas acciones propias del pensamiento cuantitativo que un individuo debe desarrollar y requiere ante cualquier otro proceso formal de aprendizaje en la matemática, como modelar o resolver situaciones problema. Éstas incluyen: seguir secuencias, reconocer patrones, estimar, visualizar imágenes; interpretar información cuantitativa, tener sentido de orientación espacial, realizar razonamientos deductivos e inductivos, e interrelacionar procedimientos y conceptos.

\section{DISEÑO METODOLÓGICO}

Este estudio se aborda desde el enfoque cuantitativo, según el nivel de medición y análisis básico de la información que se pretende desarrollar, en el cual se obtienen los datos por medio de la identificación y cuantificación de 
variables que intervienen en el fortalecimiento de las habilidades básicas del pensamiento matemático. El referente epistemológico considerado es el objetivismo, lo cual obedece a que la prioridad es la observación como actitud de conocimiento y a que el conocimiento se asume como reproducción o reflejo de hechos (Nugent, 1991). En relación con la extensión del estudio y las características de la institución en donde se lleva a cabo, se considera como una investigación de método estudio de caso cuantitativo (Yin, citado por Martínez, P. 2006), dado que: aborda una temática o fenómeno contemporáneo en un entorno real, las fronteras entre el fenómeno y su contexto no son claramente evidentes, se utilizan múltiples fuentes de datos y puede estudiarse tanto un caso único como múltiples casos (sede principal y demás sedes de UNIMINUTO). Por último, se siguió un diseño según Stanley y Campbell (2005) tipo preexperimental pretest-postest de un solo grupo.

El proyecto general de precálculo se inició en el primer semestre de 2013 con una proyección a dos años que abarcó cuatro fases: fundamentación, diseño, construcción e implementación. En la primera se definieron los referentes por tener en cuenta desde lo pedagógico, didáctico (instruccional), matemático, comunicativo y evaluativo que anteriormente se mencionaron a grandes rasgos. En la segunda fase, siguiendo los elementos claves del diseño instruccional según Jonassen (1999), los parámetros para la intervención motivacional en entornos a distancia (Huertas, 2005) y los factores que determinan el éxito formativo de los estudiantes en relación con los estilos de aprendizaje según Kolb (1984), se diseñaron nueve módulos, uno por habilidad.
Para el primer semestre de 2014 se desarrolló la fase de construcción y prueba piloto para lo cual se diseñó e implementó el primer prototipo de ambiente virtual de aprendizaje (AVA) en la plataforma Moodle de UNIMINUTO. Se incorporaron actividades, recursos, estrategias de comunicación, tutoría y evaluación para los estilos convergente, acomodador y asimilador.

El grupo piloto, conformado por 30 estudiantes del Programa de Ingeniería Agroecológica, se seleccionó al azar entre los 25 grupos de precálculo que obtuvieron un desempeño promedio básico en la prueba de ingreso 2014-1, de un total de 27 que la presentaron. Los resultados de esta fase son importantes no sólo para validar el ambiente virtual de aprendizaje sino principalmente para realizar los ajustes necesarios a la estrategia didáctica diseñada, la cual se espera fortalecer para evaluarla en la fase final de implementación, esta vez con un método cuasiexperimental tipo cuatro según Stanley y Campbell (2005), con dos grupos de estudiantes de precálculo de desempeño básico, uno de control y otro experimental con pretest-postest.

\section{ANÁLISIS DE DATOS}

Desde la estrategia didáctica propuesta. Se presenta la estrategia diseñada para la modalidad e-learning (figura 1), desarrollada en cinco etapas: familiarización, sensibilización, selección, acción praxeológica y retroalimentación; también se señalan las variables evaluadas durante el pilotaje.

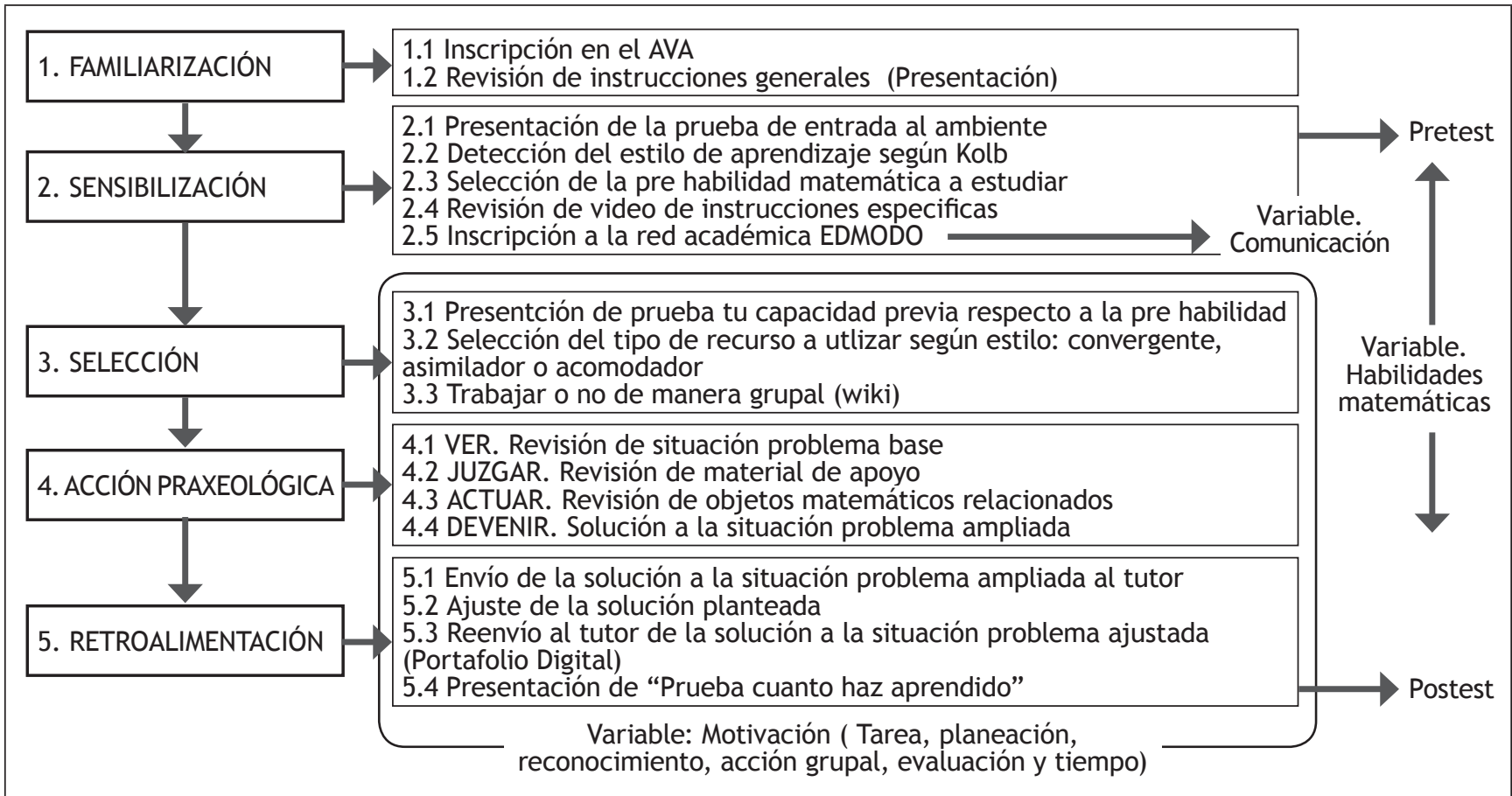

Figura 1. Propuesta didáctica por evaluar en la prueba piloto 2014-1. Fuente: autores (2014). 
Para lo motivacional y lo comunicativo se aplicaron encuestas cerradas vía online dispuestas en el AVA; y para las habilidades matemáticas se tuvieron en cuenta los resultados del pretest y el postest en la misma prueba en que se evaluaron las habilidades que se presentan en la tabla 1.

\begin{tabular}{|c|c|c|}
\hline SUBCATEGORÍA & INSTRUMENTO & PREGUNTA \\
\hline Seguir secuencias & \multirow{9}{*}{ Pretests y postets } & P1-B, P1-M, P1- A (1-2-3) \\
\hline Reconocer patrones & & P2-B, P2-M, P2- A (4-5-6) \\
\hline Estimar & & P3-B, P3-M, P3- A (7-8-9) \\
\hline Visualizar & & P4-B, P4-M, P4- A (10-11-12) \\
\hline Interpretar información & & P5-B, P5-M, P5- A (13-14-15) \\
\hline Tener sentido de orientación & & P6-B, P6-M, P6- A (16-17-18) \\
\hline Razonar deductivamente & & P7-B, P7-M, P1- A (19-20-21) \\
\hline Razonar inductivamente & & P8-B, P8-M, P8- A (22-23-24) \\
\hline Interrelacionar procedimientos & & P9-B, P9-M, P9- A (25-26-27) \\
\hline
\end{tabular}

Cada habilidad es considerada como una subcategoría para el análisis. Se evaluaron por medio de 27 preguntas en el pretest y el postest, por cada habilidad se plantearon tres preguntas con niveles de dificultad diferentes ( $B$, bajo; $M$, medio, y $A$, alto). Fuente: autores (2014).

Para iniciar la participación en el AVA, cada estudiante debía inscribirse, revisar las instrucciones y seguir la ruta didáctica expuesta en la figura 1 . En la figura 2 se presenta el menú horizontal, en el que figuran nueve actividades, cada una correspondiente a una habilidad, que el estudiante debía afrontar luego de revisar la presentación.

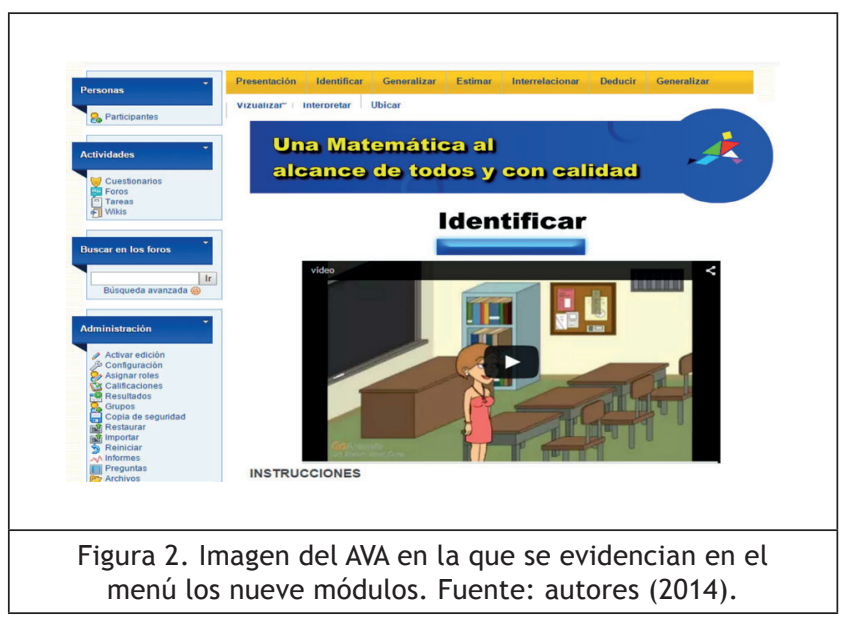

Desde la intervención motivacional. En la figura 3 se comparan los porcentajes de aceptación de los estudiantes frente a las seis acciones tenidas en cuenta como elementos motivadores en la estrategia. Se observó que el reconocimiento a la producción de los estudiantes y la evaluación tipo proceso-producto fueron los elementos que más los motivaron en la fase piloto. En otras palabras, permitirles realizar ajustes a sus tareas, avances y actividades con la debida retroalimentación del docente tutor es muy importante ya que se rompe el esquema de una prueba única o de trabajos circunscritos a una nota y se permite el mejoramiento de las propias producciones.

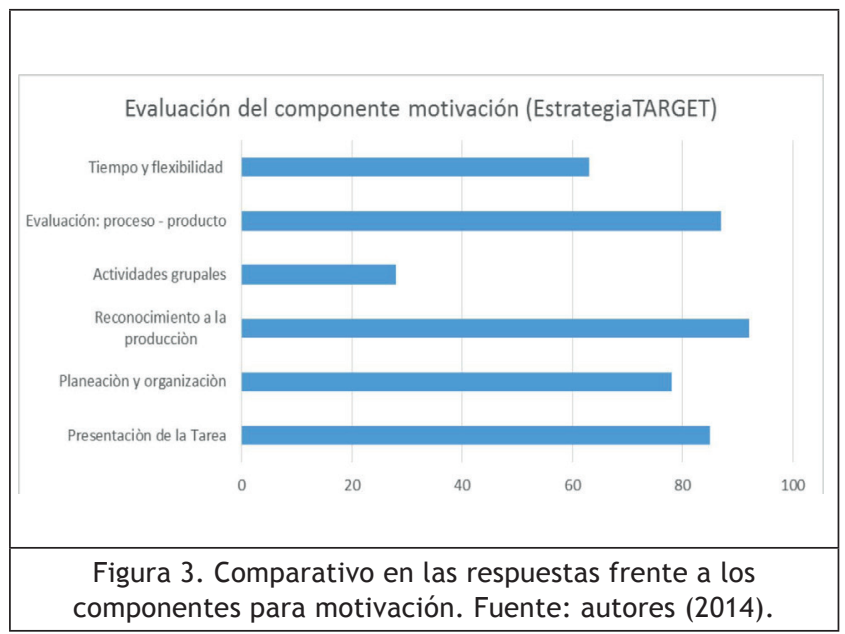

De manera específica, respecto de las tareas o actividades, la multimedia permitió su presentación de diferentes formas, lo cual es un aspecto positivo para el $85 \%$ de los estudiantes ya que están acordes con los estilos de aprendizaje para abordar la información. En cuanto a la autoridad, para el 78 \% de los estudiantes es fundamental que se presente la estructura del ambiente, su planificación y objetivos y se estimule la participación activa por medio de foros. El reconocimiento de la producción de los estudiantes mediante la retroalimentación que hacía el docente tutor en un lapso de 24 horas y que permitía la corrección de actividades hasta llegar a un producto final (portafolio digital), tuvo un nivel de calificación pertinente para el $92 \%$ de los estudiantes. Las acciones grupales tuvieron una aceptación del 28 $\%$, lo cual indica que es necesario fortalecer las que se propusieron e incentivar el trabajo colaborativo. El proceso evaluativo centrado en la relación procesoproducto, en la cual el estudiante podía mejorar su propuesta de solución a la situación problema, tuvo 
una valoración muy favorable equivalente al $87 \%$. Por último, en relación con el tiempo y la flexibilidad para que los estudiantes desarrollaran cada módulo (apertura en el AVA de dos semanas), de acuerdo con su disponibilidad personal, se logró un nivel de aceptación del $63 \%$; varios estudiantes mencionaron que no tenían la suficiente disciplina.

Desde el apoyo comunicativo. En la figura 4 se muestra el tipo de interacción que se llevaba a cabo con los estudiantes en la red académica Edmodo.

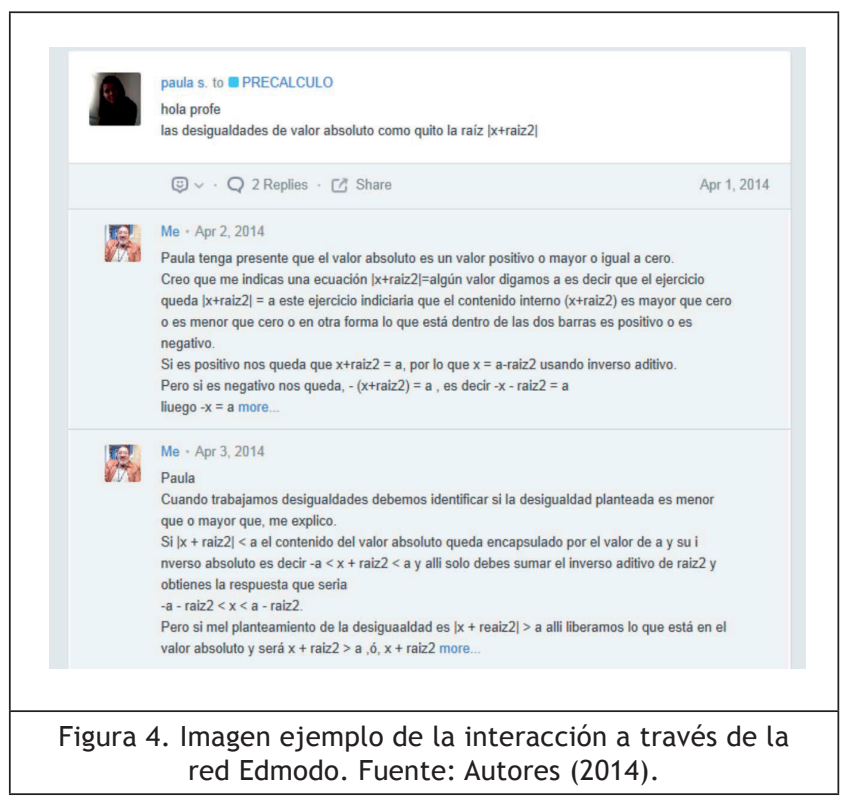

La pertinencia de la red académica Edmodo (herramienta libre para PC y dispositivos móviles) se evaluó como sistema tutorial en relación con una opinión de "muy de acuerdo" en los estudiantes: el docente tutor incentiva a los estudiantes a participar activamente en el entorno ( $86 \%$ ), el nivel de apoyo que se brindó en la red fue oportuno a la hora de buscar opinión experta (75\%), el tutor es un modelo para seguir en el desarrollo de las actividades (68 $\%)$, analiza y cuestiona la retroalimentación dada por el tutor y a partir de ella acude a la acción (74\%). A pesar de estos resultados, para la etapa inicial se sugiere que en la implementación final del proyecto se utilicen directamente las herramientas comunicativas dispuestas en Moodle, es decir en el AVA. Lo anterior se debe a que una herramienta externa, aunque resulta agradable para los estudiantes, requiere mucho más trabajo del docente tutor ya que en los foros del AVA se terminaba preguntando en muchas ocasiones lo mismo que en la red académica.

Desde las habilidades básicas. En la figura 5 se compara el desempeño general de los estudiantes del grupo piloto entre el pretest y el postest. Se puede observar que el puntaje promedio pasó de 13,6 a 22,3. A pesar del aumento, ambos promedios quedaron por debajo de 25, que era el límite superior para desempeño básico. Por otra parte, mientras que 29 estudiantes se clasificaron en nivel básico en el pretest y sólo uno en medio, en el postest 14 permanecieron en básico y 16 llegaron al nivel medio.

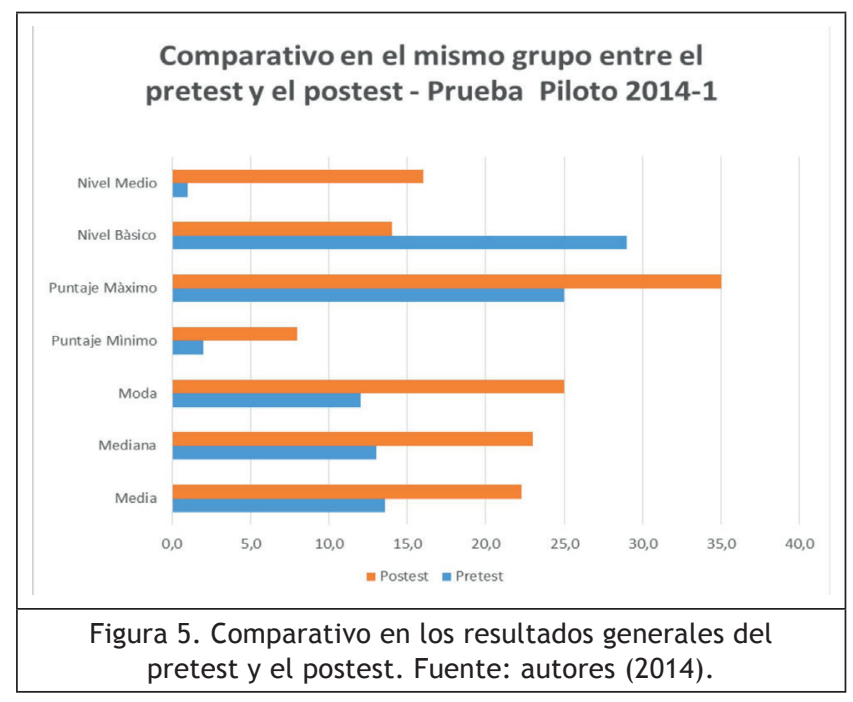

Respecto de las habilidades básicas en matemáticas, en la figura 6 se muestra un comparativo entre el pretest y el postest en relación porcentual de estudiantes.

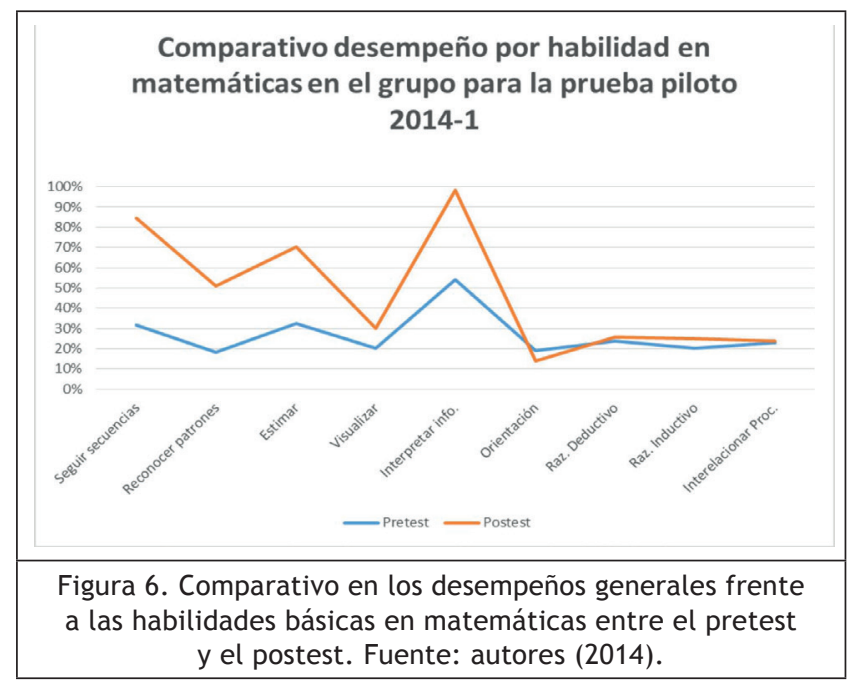

Se evidencia que hubo aumento significativo en el desempeño frente a habilidades como: seguir secuencias ( $53 \%$ ), reconocer patrones (33\%), estimar (38\%) e interpretar información cuantitativa (44\%). Para visualización, razonamiento deductivo e inductivo e interrelacionar procedimientos, los desempeños casi permanecieron constantes o aumentaron en mínimas proporciones. Llama la atención que en tener sentido de orientación hubo disminución. 


\section{CONCLUSIONES}

A partir de los resultados parciales obtenidos en la prueba piloto aplicada durante el primer semestre de 2014 se encontró lo siguiente:

- La estrategia didáctica utilizada para incentivar la motivación ha sido favorable principalmente en cuanto al reconocimiento a la producción de los estudiantes y la evaluación en mejoramiento de proceso-producto. Se deben reevaluar las actividades grupales sugeridas, ya que para los estudiantes no fueron elementos motivadores contundentes.

- Con respecto al apoyo comunicativo, el papel del docente como agente que incentiva la participación de los estudiantes es el eje fundamental. Así lo demostraron los criterios considerados en la encuesta, aunque operativamente es un elemento que se debe manejar en el AVA dado que el uso de una herramienta secundaria exige mayores tiempos de dedicación al tener que responder y dar seguimiento a las dos herramientas.

- El impacto de la estrategia didáctica diseñada fue positivo ya que hubo un aumento en más del $33 \%$ en habilidades como seguir secuencias, reconocer patrones, estimar e interpretar información cuantitativa. Es necesario revisar aspectos en las etapas de sensibilización, selección y retroalimentación, principalmente, ya que a lo largo de la prueba piloto se evidenció que algunos módulos no tuvieron para los estudiantes el impacto necesario o claridad en los recursos utilizados y se hizo visible en las mínimas transformaciones en el desempeño entre el antes y el después de habilidades como visualización, razonamiento deductivo e inductivo e interrelación de procedimientos. Es necesario revisar el módulo de orientación ya que no aumentó sino que disminuyó el desempeño de los estudiantes.

- Finalmente, a pesar de que el porcentaje de estudiantes que pasaron del nivel básico a medio fue notorio, el puntaje promedio del grupo piloto continuó dejándolo en un nivel básico como en la prueba de entrada o pretest. Dicha situación exige la necesidad de involucrar recursos o actividades de mayor impacto para los estudiantes pero sobre todo que se encuentren ancladas con las temáticas que desarrollan de forma paralela en sus cursos de precálculo y geometría.

- Durante un semestre regular es recomendable analizar el momento pertinente para implementar la estrategia, de manera que no se convierta en una asignatura más para los estudiantes y se pierda su sentido de apoyo. Por ejemplo, es recomendable un mes antes de iniciar el semestre académico, de modo que los estudiantes la utilicen como nivelación o adaptación antes de tomar su curso formal de matemáticas. Se espera que con la implementación de la estrategia durante el semestre 2014-II en un grupo experimental sea posible dar cuenta de otros aspectos como los beneficios y limitaciones de la plataforma utilizada, la sincronía y asincronía del trabajo docente, la labor de tutoría y el papel de las herramientas de comunicación, entre otros.

\section{REFERENCIAS}

1. Alsina, A. \& Domingo, M. (2007). Cómo aumentar la motivación para aprender matemáticas. Revista Suma, Universidad de Gerona.

2. Ayala, M. (2010). Estilos de aprendizaje y comunicación en la educación a distancia. Revista Estilos de Aprendizaje, 5 (5), pp. 1-21. Recuperado de http://www.ruv.itesm.mx/convenio/catedra/ recursos/material/re_20.pdf.

3. Argüelles, D. \& Nagles, N. (2010). Estrategias para promover procesos de aprendizaje autónomo (4.a ed.). Colombia: Universidad EAN.

4. Coll, C. \& Monereo, C. (eds.) (2008). Psicología de la educación virtual. Aprender y enseñar con las tecnologías de la información y la comunicación. Madrid: Morata.

5. Jonassen, D. (1999). El diseño de entornos constructivistas de aprendizaje. En: Reigeluth, Ch. (eds.). Diseño de la instrucción. Teorías y modelos. Un nuevo paradigma de la teoría de la instrucción. Parte I, pp. 225-249. Madrid: Aula XXI Santillana.

6. Juliao, C. (2011). El enfoque praxeológico (1. a ed.). Bogotá: Corporación Universitaria Minuto de Dios UNIMINUTO.

7. Huertas, J. (2001). Motivación. Querer aprender. Buenos Aires: Ed. Aique.

8. Kolb, D. (1993). Learning styles. David Kolb's learning styles model and experiential learning theory (ELT). Recuperado de http://www. businessballs.com/kolblearningstyles.htm el 20 de abril de 2013.

9. Nugent, J. (1991). Las perspectivas del mundo de la vida en las investigaciones de las ciencias sociales. Debates en Sociología, 16, pp. 1-27. Recuperado de http://revistas.pucp.edu. pe/index.php/debatesensociologia/article/ view/6590/6683 
10. Sharma, S.V. (2006). High school students interpreting tables and graphs: implications for research. International Journal of Science and Mathematics Education, 4, pp. 241-268.

11. Sousa, D. (2007). How the brain learns. Alexandria, VA: Association for Supervision and Curriculum Development.

12. Stanley, J. \& Campbell, D. (2005). Diseños experimentales y cuasiexperimentales en la investigación social. Buenos Aires: Ammorrortu editors.
13. UNIMINUTO. (2014). Modelo educativo. Bogotá: Uniminuto.

14. Valls, P., Díaz, F. \& Hernández, G. (1993). Estrategias docentes para un aprendizaje significativo. Una interpretación constructivista (2.a ed.). Colombia: Editorial Mc Graw Hill.

15. Ventura, A., Palou, I. \& Széliga, C. (Julio-diciembre 2014). Estilos de aprendizaje y enseñanza en ingeniería: una propuesta de educación adaptativa para primer año. Revista Educación en Ingeniería, 9(18), pp. 178-189. 